\title{
Análise da aplicabilidade da técnica da dupla camada para o alívio de tensões em juntas soldadas de aços microligados
}

\author{
Leandro Macedo Cozza ${ }^{1 *}$ (D) \\ Jorge Luis Braz Medeiros ${ }^{1}$ \\ Fabio Augusto Dornelles do Amaral ${ }^{\perp}$ \\ Luciano Volcanoglo Biehl ${ }^{1}$ \\ Sérgio da Silva Cava ${ }^{2}$ \\ Fábio Calcagno Riemke ${ }^{2}$ \\ Demostenes Ferreira Filho ${ }^{3}$
}

\section{Resumo}

A técnica da dupla camada busca promover uma adequada sobreposição dos ciclos térmicos de tal forma que a segunda camada promova o refino e o revenimento da região de crescimento de grão da zona afetada pelo calor da primeira camada. Esta técnica surge como opção ao tratamento térmico para alívio de tensões, quando o mesmo se apresenta como uma alternativa onerosa. Além das questões econômicas, deve-se levar em consideração o material de base utilizado na soldagem. O aço ASTM A131 grau AH 36 não é indicado a sofrer alívio de tensões, já que pode deteriorar suas propriedades mecânicas. Diante disto, este trabalho teve por objetivo avaliar o efeito da dupla camada em substituição ao referido tratamento. Para isto foram realizadas soldagens de três corpos de prova (referência, TTAT e dupla camada) e comparação dos perfis de dureza e microestrutura. Os resultados indicaram um aumento no tamanho de grão da junta com dupla camada em relação à junta de referência. Os valores de dureza foram compatíveis com um revenimento da zona afetada pelo calor da primeira camada contribuindo para utilização da dupla camada neste contexto.

Palavras-chave: Soldagem; Tratamento térmicos; Alívio de tensões.

\section{Analysis of the applicability of the double layer technique for the stress relief in welded joints of microalloyed steels}

\begin{abstract}
The double layer technique seeks to promote adequate overlap of thermal cycles such that the second layer promotes the refine and temper of the grain growth region of the heat affected zone of the first layer. This technique appears as alternative to stress relief heat treatment, when this treatment is a costly alternative. In addition to economic issues, consideration should be given to the base material used. In the case of the ASTM A131 grade AH 36 steel, it's not indicated to perform this treatment because this may deteriorate its mechanical properties. Given this, this work aimed to evaluate the effect of double layer in substitution to stress relief treatment. For this, three proof bodies were welded (reference, HTSR and double layer) and compared the hardness and microstructure profiles. The results indicated a increase in the grain size of the double layer joint in relation to the reference joint. The hardness values were compatible with tempering of the heat affected zone of the first layer contributing to the use of the double layer in this context.
\end{abstract}

Keywords: Welding; Hear treatment; Stress relief.

\footnotetext{
'Programa de Pós-graduação em Engenharia Mecânica-PPMec, Escola de Engenharia, Universidade Federal do Rio Grande - FURG, Rio Grande, RS, Brasil.

${ }^{2}$ Programa de Pós-graduação em Ciência e Engenharia de Materiais - PPGCEM, Centro de Desenvolvimento Tecnológico, Universidade Federal de Pelotas-UFPEL, Pelotas, RS, Brasil.

${ }^{3}$ Escola de Engenharia Elétrica, Mecânica e de Computação, Universidade Federal de Goiás - UFG, Goiânia, GO, Brasil.

*Autor correspondente: lcozza@bol.com.br
}

2176-1523 (C) 2021. Cozza et al. Publicado pela ABM. Este é um artigo publicado em acesso aberto (Open Access) sob a licença Creative Commons Attribution, que permite uso, distribuição e reprodução em qualquer meio, sem restrições desde que o trabalho original seja corretamente citado. 


\section{Introdução}

A técnica da dupla camada se baseia na deposição controlada dos passes da segunda e primeira camadas e da relação de energia de soldagem de tal forma que ocorra então o refino e o revenimento da zona de crescimento de grão afetada pelo calor da primeira camada $\left(\mathrm{ZAC}-\mathrm{GG}_{1}\right)[1]$.

Esta técnica especial de soldagem surge como alternativa ao tratamento térmico para alívio de tensões, quando o mesmo acarreta em aumento de custos relacionados ao processo produtivo (por exemplo: contratação de uma empresa especializada em tratamentos térmicos se a empresa não possuir um setor apropriado). Somados a este fato, as estruturas e/ou tubulações que demandam este procedimento podem apresentar grandes dimensões que inviabilizam a utilização de fornos ou mantas isolantes. A técnica da dupla camada, neste caso, se utiliza apenas do custo de mão de obra do operador/soldador.

O material de base (ASTM A131 grau AH 36), empregado na indústria metalmecânica como estrutura metálica na fabricação e montagem em cascos de plataformas de petróleo, quando submetido a soldagem não é indicado a sofrer tratamento térmico convencional. O mesmo é produzido por TMCP (thermomechanical controlled processing), portanto não indicado a ser tratado termicamente por normalização, normalização seguida por revenimento, ou por têmpera e revenimento. Estes tratamentos térmicos podem deteriorar as propriedades mecânicas de tração e/ou tenacidade. Neste caso o único tratamento possível de ser realizado é o tratamento térmico para alívio de tensões (TTAT) através de um recozimento subcrítico com temperatura recomendada mantida abaixo dos $600^{\circ} \mathrm{C}$ [2].

Tsay et al. [3] trabalharam com um aço TMCP, com carbono equivalente $\left(\mathrm{C}_{\mathrm{eq}}\right)$ de 0,38 (semelhante ao material deste estudo). Os autores relatam que o TTAT $\left(600^{\circ} \mathrm{C} / 2 \mathrm{~h}\right)$ não alterou significativamente a tenacidade no metal de base e na ZAC. Neste mesmo trabalho a análise metalográfica indicou que a microestrutura também não foi significativamente alterada.

Cozza et al. [4] também estudaram a influência do TTAT em um aço microligado. Os resultados encontrados verificaram que o tamanho de grão não foi alterado significativamente após a aplicação do referido tratamento.

Com relação a microestrutura derivada da soldagem do aço AH36, é importante destacar a análise realizada por Ribeiro et al. [5]. Os pesquisadores verificaram a presença dos seguintes constituintes: agregado ferrita-carbonetos, ferrita poligonal, ferrita de segunda fase alinhada e não alinhada e ainda presença de constituinte martensita-austenita (MA) na zona de crescimento de grão afetada pelo calor (ZAC-GG). Essa investigação é pertinente para a posterior comparação dos microconstituintes encontrados neste estudo, bem como, seu efeito em relação ao tratamento térmico e a técnica da dupla camada.

Esta publicação continua e complementa o trabalho desenvolvido por Cozza et al. [6]. Neste estudo os autores avaliaram o efeito de diferentes relações de energias de soldagem para aplicação na técnica da dupla camada para aplicação em um aço ASTM A131 Grau AH36. Os resultados indicaram que as relações de energias de soldagem com 5/14

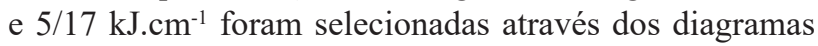
de decisão apresentando valores de afastamento positivos nos critérios baseados na macrografia e na microdureza. Porém a combinação de $5 / 14 \mathrm{~kJ} . \mathrm{cm}^{-1}$ foi a escolhida, já que, apresentou o maior afastamento no critério baseado na microdureza, indicando uma maior capacidade da zona não endurecida da segunda camada poder revenir a zona endurecida da primeira.

Desta forma o objetivo central neste caso é avaliar o efeito da aplicação da técnica da dupla camada, em substituição ao tratamento térmico para alívio de tensões, através da comparação das propriedades mecânicas (dureza e microdureza) e microestrutura na soldagem de corpos de prova com aplicação de TTAT e com a dupla camada. Em consequência disto espera-se que ocorra então o revenimento e o refino microestrutural na zona afetada pelo calor no aço ASTM A131 Grau AH36 na tentativa de reduzir a microdureza e distorções relacionadas as tensões residuais.

\section{Metodologia}

\subsection{Materiais}

\subsubsection{Metal de base e de adição}

O metal de base utilizado neste trabalho foi o aço ASTM A131 Grau AH36, produzido via TMCP e fornecido sob a forma de chapa laminada de $750 \times 1300 \times 12,5(\mathrm{~mm})$. A fim de obter o controle das variáveis de soldagem, o que pode ser considerado crucial nesta pesquisa, optou-se por escolher o processo de soldagem Gas Metal Arc Welding (GMAW) semiautomático com metal de adição AWS ER70S-6 de 1,2 mm de diâmetro com $100 \%$ de $\mathrm{CO}_{2}$ como gás de proteção.

\subsection{Métodos}

\subsubsection{Soldagem preliminar}

Os resultados para a soldagem preliminar e critérios para análise dos diagramas de decisão (incluindo a caracterização do metal de base) foram discutidos e abordados por Cozza et al. [6]. Em seu trabalho foi realizado um cordão de soldagem com deposição sobre chapa de dimensões $150 \times 80 \times 12,5(\mathrm{~mm})$ na posição plana com objetivo de encontrar uma relação entre as energias da primeira e segunda camada que satisfaça os critérios de avaliação (critério da microdureza e da macrografia). Neste quesito foram testados quatro níveis de energias de soldagem com a variação da 
energia controlada pela velocidade de soldagem. Os corpos de prova foram soldados com distância bico de contato-peça (DBCP) de $12 \mathrm{~mm}$ e vazão de gás de $161 \cdot \mathrm{min}^{-1}$. A Tabela 1 apresenta os parâmetros de soldagem e as energias de soldagem calculadas.

Após a soldagem das chapas de teste foram retiradas as amostras para realização das medições de microdureza afim de avaliar os tamanhos das zonas endurecidas (ZE) e zonas não endurecidas (ZNE). As mesmas amostras também foram utilizadas para medição dos parâmetros (ZAC-GG, ZAC-GF, reforço (R) e penetração (P)) oriundos do ensaio macrográfico. Os perfis de microdurezas bem como os dos perfis oriundos das macrografias foram submetidos aos critérios representados nas Equações 1 a 4 .

- Critério do Perfil do Cordão baseado na Microdureza

$$
\begin{aligned}
& \left(P Z N E_{2}\right)>\left(P Z E_{1}\right) \\
& \left(R_{1}+P_{1}\right)>\left(P Z E_{2}\right)
\end{aligned}
$$

onde: $\mathrm{PZNE}_{2}$ representa a profundidade da zona não endurecida da segunda camada, $\mathrm{PZE}_{1}$ representa a profundidade da zona endurecida da $1^{\circ}$ camada, $\mathrm{R}_{1}$ representa a altura do reforço da primeira camada e $\mathrm{P}_{1}$ representa a medida da penetração da primeira camada.

- Critério do Perfil do Cordão baseado na Macrografia

$$
\left(P Z A C-G F_{2}\right)>\left(P Z A C-G G_{1}\right)
$$

$$
\left(Z F_{1}\right)>\left(P Z A C-G G_{2}\right)
$$

onde: $\mathrm{ZF}_{1}$ representa o somatório do reforço e da penetração na primeira camada, $\mathrm{PZAC}-\mathrm{GF}_{2}$ a profundidade da zona afetada pelo calor com granulação fina da segunda camada,

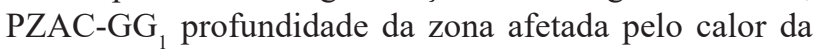
granulação grosseira da primeira camada e PZAC- $\mathrm{GG}_{2}$ representa a profundidade da zona afetada pelo calor da granulação grosseira da segunda camada.

O referido estudo demonstrou que a relação de energia mais adequada foi a relação $5 / 14 \mathrm{~kJ} . \mathrm{cm}^{-1}$.

\subsubsection{Soldagem com as juntas chanfradas}

Antes da soldagem das juntas foi realizada a preparação do chanfro reto da junta chanfrada para a aplicação da técnica da dupla camada. Este processo foi realizado em duas etapas (Figura 1 e 2):

- Primeira camada: nesta etapa foram adicionados dois passes de solda com a energia escolhida para a primeira camada $\left(5 \mathrm{~kJ} . \mathrm{cm}^{-1}\right)$;

- Segunda camada: após a primeira etapa foi aplicado um passe com a energia de $14 \mathrm{~kJ} . \mathrm{cm}^{-1}$ caracterizando assim a dupla camada. Posteriormente, foi a realizada a usinagem do excesso de solda $(2 \mathrm{~mm})$ para nivelamento do chanfro reato da junta.

Para avaliar a viabilidade do procedimento de soldagem multipasses sem TTAT foram soldadas três juntas conforme disposto a seguir:

- Referência: soldada sem a aplicação de TTAT ou dupla camada;

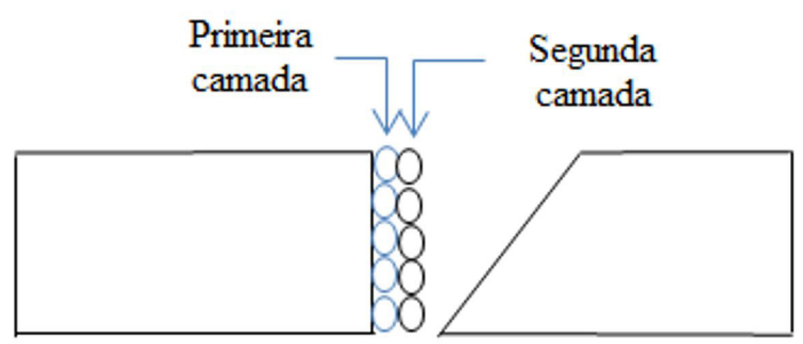

Figura 1. Representação esquemática do chanfro reto com aplicação da dupla camada - vista lateral do corpo de prova.

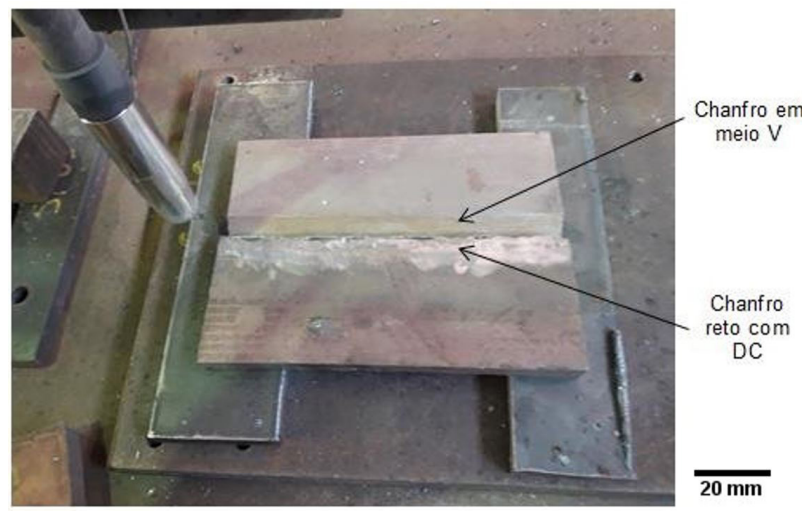

Figura 2. Montagem da junta para soldagem com chanfro preparado pela técnica da dupla camada.

Tabela 1. Parâmetros de soldagem

\begin{tabular}{ccccc}
\hline Corpo de Prova & Tensão (V) & Corrente (A) & $\begin{array}{c}\text { Velocidade de Soldagem } \\
\left(\mathbf{c m . m i n} \mathbf{m}^{-1}\right)\end{array}$ & $\begin{array}{c}\text { Energia de Soldagem } \\
\left(\mathbf{k J . c m} \mathbf{H}^{-1}\right)\end{array}$ \\
\hline 1 & 24,3 & 125 & 39,6 & 5 \\
2 & 25,0 & 124 & 21,6 & 9 \\
3 & 24,4 & 128 & 13,2 & 14 \\
4 & 24,2 & 126 & 10,7 & 17 \\
\hline
\end{tabular}


- TTAT: soldada com os mesmos parâmetros da Referência, porém com posterior tratamento térmico de alivio de tensões;

- Dupla camada: antes da soldagem foi realizada a preparação do chanfro reto da junta chanfrada para a aplicação da técnica da dupla camada.

A Figura 3 apresenta o croqui da junta chanfrada com suas dimensões.

Os parâmetros para a soldagem das juntas chanfradas são mostrados na Tabela 2. Para isso foram tomados como referência os valores contidos no trabalho de Cruz [7] com ajustes em virtude dos parâmetros específicos da soldagem utilizada nesta pesquisa. Os corpos de prova foram soldados com distância bico de contato-peça (DBCP) de $14 \mathrm{~mm}$ (controlado através da utilização de um padrão) e vazão de gás de 16 1/min.

Na Figura 4 apresenta-se a sequência de soldagem utilizada neste trabalho. Após a realização do passe de acabamento a chapa foi virada para a realização de goivagem e posteriormente soldagem do segundo passe de raiz (R2). A utilização do processo de goivagem (abertura da raiz) foi importante uma vez que permitiu a análise da raiz (R1). Com intuito de evitar e também corrigir descontinuidades

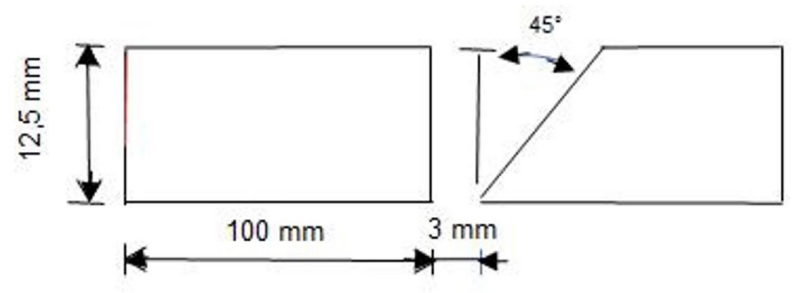

Figura 3. Croqui da junta chanfrada.

Tabela 2. Parâmetros de soldagem para o enchimento das juntas

\begin{tabular}{cccc}
\hline Passes & Tensão (V) & Corrente (A) & $\begin{array}{c}\text { Velocidade de } \\
\text { Soldagem } \\
\left(\mathbf{c m} . \text { min }^{-1}\right)\end{array}$ \\
\hline R1 & 25,0 & 90 & 13 \\
R2 & 25,0 & 130 & 16 \\
2 & 25,0 & 130 & 16 \\
3 & 25,0 & 130 & 16 \\
4 & 25,0 & 130 & 16 \\
5 & 25,0 & 130 & 25 \\
\hline
\end{tabular}

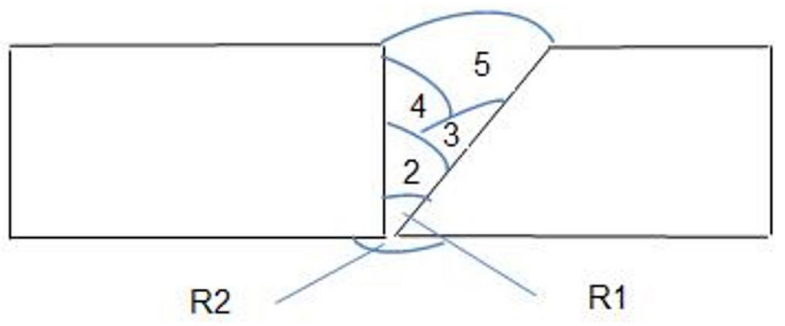

Figura 4. Sequência de soldagem para as juntas chanfradas. presentes realizou-se a soldagem da contra solda (R2) onde se depositou um passe de solda adicional com os mesmos parâmetros da soldagem de raiz inicial.

\subsubsection{Tratamento térmico para alívio de tensões}

A junta soldada denominada TTAT foi tratada termicamente em um forno, em ambiente não protegido por 90 minutos a uma temperatura de $650{ }^{\circ} \mathrm{C}$ conforme metodologia aplicada por Cruz [7] e Azevedo [8].

\subsubsection{Caracterização metalúrgica e análise de tamanho de grão}

As três amostras $(160 \times 15 \times 12,5) \mathrm{mm}$ foram retiradas transversalmente a linha de solda com descarte de $(160 \times 10$ $\times 12,5) \mathrm{mm}$ de cada lado da junta. Então foram preparadas para análise metalográfica através dos procedimentos de corte, lixamento, polimento e ataque químico com nital $2 \%$ e observadas por meio de microscopia ótica.

Para a análise do tamanho de grãos ferríticos foi utilizado o método planimétrico que consistiu na contagem do número de grãos dentro de uma área conhecida em três regiões diferentes $(1 / 4,1 / 2$ e $3 / 4$ da espessura) da amostra. A região foco da observação foi a ZAC-GG das juntas com

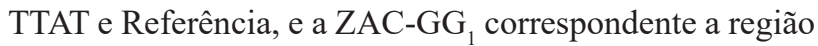
da primeira camada para o corpo de prova da dupla camada que será revenida e refinada pela segunda camada.

\subsubsection{Medição da dureza Vickers}

Para a medição de dureza foram realizadas medições e comparações entre as durezas encontradas para as amostras sem TTAT, com TTAT e com a técnica da dupla camada em três regiões diferentes $(1 / 4,1 / 2 \mathrm{e} 3 / 4$ da espessura) da amostra. Para tal foram aplicadas impressões com cargas de $2 \mathrm{~kg}$ aplicadas durante 10 segundos e localizadas desde a linha de fusão até o metal de base distanciadas entre si de $0,5 \mathrm{~mm}$.

\subsubsection{Análise estatística de dados}

Para avaliar o efeito da significância entre o tamanho do grão e a dureza entre a junta de referência, junta com TTAT e com a dupla camada foi utilizada a Análise de Variância (ANOVA) de fator único. Esta análise estatística permite o seguinte teste de hipóteses:

$\mathrm{H}_{0}: \mu_{1}=\mu_{2}=\mu_{3}$ : é a hipótese nula, ou seja, a que se quer rejeitar: As diferenças entre as médias não são significativas;

$\mathrm{H}_{1}$ : Existe pelo menor uma diferença significativa entre as médias.

Se o valor de $\mathrm{p}$ for menor que o nível de confiança adotado $(\alpha=0,05)$, rejeita-se a hipótese nula em que as diferenças entre as médias destas três variáveis não são significativas. Quando houver pelo menos uma diferença significativa, deverão se investigar quais são os grupos que apresentam as diferenças entre as médias. Essa análise foi 
realizada por um método complementar à ANOVA, ou seja, o teste de Tukey. Para isto se utilizou a diferença mínima significativa (d.m.s) conforme a Equação 5:

$$
d . m . s=q \sqrt{\frac{Q M R}{n^{\circ} \text { repetições }}}
$$

onde: $\mathrm{q}=$ valor tabelado para o teste de Tukey; $\mathrm{QMR}=$ Quadrado médio do resíduo (ANOVA); $\mathrm{n}^{\circ}$ de repetições $=$ número de elementos em cada coluna.

A regra de comparação do teste pode ser visualizada como uma diferença entre duas médias quaisquer comparando com o d.m.s (Equações 6 e 7):

Quando $\mu_{\mathrm{A}} \neq \mu_{\mathrm{B}}$

$$
\left|x_{A}-x_{B}\right| \geq \text { d.m.s }
$$

$$
\begin{aligned}
& \text { Quando } \mu_{\mathrm{A}}=\mu_{\mathrm{B}} \\
& \left|x_{A}-x_{B}\right| \leq \text { d.m.s }
\end{aligned}
$$

onde: $\left|\mathrm{x}_{\mathrm{A}}-\mathrm{x}_{\mathrm{B}}\right|=$ diferença entre duas médias de grupos diferentes; $\mu_{\mathrm{A}}=$ média do grupo $\mathrm{A} ; \mu_{\mathrm{B}}=$ média do grupo $\mathrm{B}$.

\section{Resultados e discussão}

\subsection{Análise macro e microestrutural}

\subsubsection{Comparação entre as juntas de referência, com TTAT e dupla camada}

Na Figura 5 é investigada uma comparação do comportamento macro e microestrutural da ZAC-GG entre as amostras de referência, com tratamento térmico e na

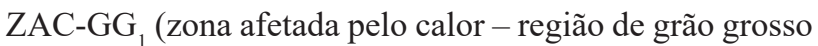
da primeira camada) da amostra com aplicação da técnica da dupla camada.

A microestrutura do corpo de prova soldado com dupla camada apresentou transformações microestruturais gerando regiões refinadas na $\mathrm{ZAC}-\mathrm{GG}_{1}$ ocasionadas pelos ciclos térmicos oriundos da zona de refino de grão (ZAC-GF) da segunda camada [9]. As transformações microestruturais nessa região são afetadas pelo ciclo térmico e pelos passes subsequentes.

Neste caso, o pico de temperatura do último passe excede a temperaturas da região intercritica (fases ferrita e austenita) e com o resfriamento a austenita resultante se decompõe em ferrita alinhada com carbonetos (FS (A)), ferrita não alinhada com carbonetos FS (NA), agregado ferrita-carboneto (FC) e ainda um percentual de constituinte MA. Ribeiro et al. [5] e Cozza et al. [4] e encontraram os mesmos microconstituintes para a soldagem deste mesmo tipo de aço.

Verificam-se os mesmos principais constituintes da ZAC-GG nas amostras com TTAT comprovando que o

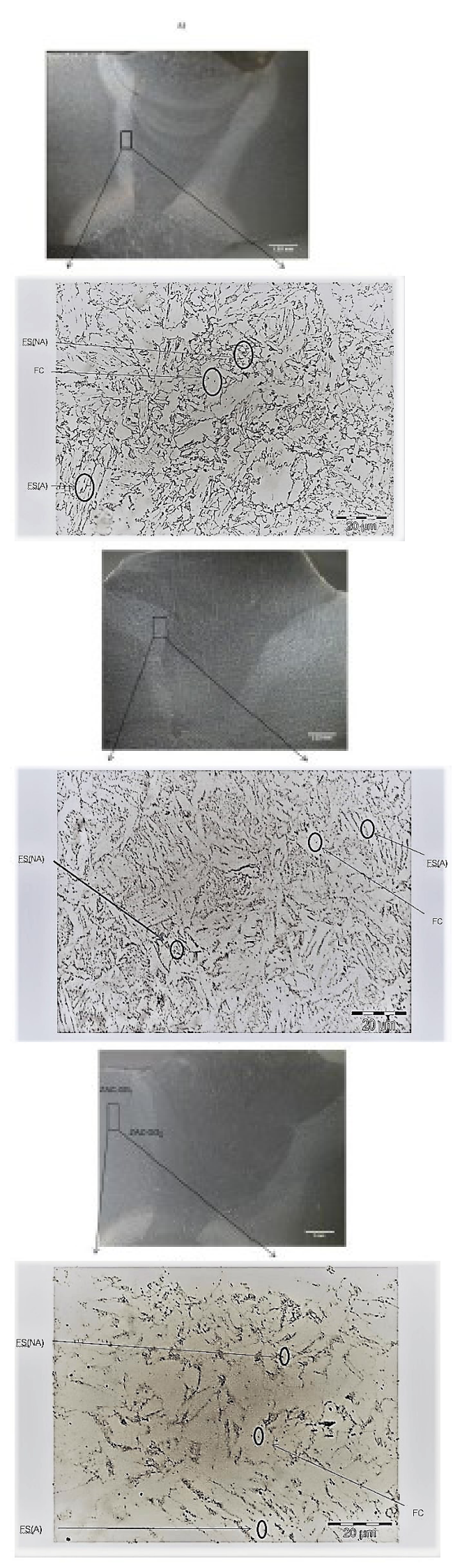

Figura 5. Macro e microestrutura do corpo de prova: (a) amostra de referência; (b) com TTAT; e (c) dupla camada. 
tratamento térmico pós-soldagem não altera o comportamento microestrutural do aço estudado no presente trabalho. Estes resultados são consistentes com as observações metalográficas de Tsay et al. [3] que demonstraram que a microestrutura não teria sido alterada pelo TTAT. Ribeiro et al. [5] e Cozza et al. [4] encontraram os mesmos resultados para a soldagem deste mesmo tipo de aço.

A Tabela 3 apresenta um quadro resumo da variação do tamanho de grão ferritico encontrado entre as juntas analisadas.

A Figura 6 apresenta o quadro resumo da análise estatística ANOVA fator único para o tamanho do grão.

Como o valor de $\mathrm{P}(0,000358)$ foi menor que o nível de confiança adotado as a hipótese nula foi rejeitada e as diferenças entre as medidas foram consideradas significativamente diferentes. A Tabela 4 mostra os resultados para a comparação realizada pelo teste de Tukey afim de determinar quais dos grupos apresentam diferenças significativas.

Embora identificando-se um aumento estatisticamente significativo no tamanho de grão com a aplicação do método da dupla camada, o mesmo mantem-se dentro da classificação como grãos finos - extrafinos, resultando em valores de dureza compatíveis com um revenimento da zona afetada

Tabela 3. Quadro resumo do tamanho de grão ferrítico da ZAC-GG para as amostras

\begin{tabular}{lccc}
\hline ZAC-GG & $\begin{array}{c}\text { Junta de } \\
\text { Referência } \\
(\boldsymbol{\mu m})\end{array}$ & $\begin{array}{c}\text { Junta com } \\
\text { TTAT }(\boldsymbol{\mu m})\end{array}$ & $\begin{array}{c}\text { Junta com } \\
\text { dupla camada } \\
(\boldsymbol{\mu m})\end{array}$ \\
\hline Medição 1 & 12,71 & 12,25 & 15,24 \\
Medição 2 & 11,65 & 12,71 & 16,82 \\
Medição 3 & 12,44 & 12,68 & 15,96 \\
Média & $\mathbf{1 2 , 2 7 \pm 0 , 4 5}$ & $\mathbf{1 2 , 5 5} \pm \mathbf{0 , 2 1}$ & $\mathbf{1 6 , 0 1} \pm \mathbf{0 , 6 5}$ \\
\hline
\end{tabular}

pelo calor da primeira camada, o que contribui para que técnica da dupla camada possa ser utilizada satisfatoriamente.

\subsection{Análise das medições de dureza}

\subsubsection{Comparação da dureza média entre as juntas de referência, com TTAT e dupla camada}

Na Figura 7 são apresentados os perfis de dureza média Vickers levantados na seção transversal das amostras da junta de referência, com TTAT e com aplicação da dupla camada desde a linha de fusão até o metal de base.

A Figura 8 apresenta o quadro resumo da análise estatística ANOVA fator único para a dureza.

Como o valor de $\mathrm{P}(0,335794)$ foi maior que o nível de confiança adotado as a hipótese nula foi aceita indicando que as diferenças entre as durezas não foram consideradas significativamente diferentes. O valor máximo da dureza média (225 HV2) diminui tanto para a amostra com tratamento de alívio de tensões (220 HV2) quanto na aplicação da dupla camada (221 HV2). Os resultados são coerentes com os encontrados por Aloraier et al. [10] e Cavalcante et al. [11]. Ambos os autores, utilizando a técnica da dupla camada, verificaram eficácia na redução nas medidas de dureza. As amostras com utilização do tratamento térmico convencional apresentaram dureza mais baixa, porém com valores em ambas as técnicas aceitáveis.

Silva et al. [12] e Farias e Aguiar [9] encontraram em seus respectivos trabalhos a respeito de dupla camada resultados semelhantes no que diz respeito a diminuição da dureza, porém com regiões com granulação grosseira. $\mathrm{O}$ primeiro verificou que embora para as relações de energias $5 / 10$ e $15 / 5$ tenha havido o revenimento e consequente

\begin{tabular}{|c|c|c|c|c|c|c|}
\hline \multicolumn{5}{|l|}{ RESUMO } & & \\
\hline Grupo & Contagem & Soma & Média & Variância & & \\
\hline Junta de referência & 3 & 36,80 & 12,2666667 & 0,303433 & & \\
\hline Junta com TTAT & 3 & 37,64 & 12,5466667 & 0,066233 & & \\
\hline Junta com DC & 3 & 48,02 & 16,0066667 & 0,625733 & & \\
\hline \multicolumn{7}{|l|}{ ANOVA } \\
\hline Fonte da variação & $S Q$ & $g l$ & $M Q$ & $F$ & valor- $P$ & F critico \\
\hline Entre grupos & 26,0376 & 2 & 13,0188 & 39,23689 & 0,000358 & 5,143253 \\
\hline Dentro dos grupos & 1,9908 & 6 & 0,3318 & & & \\
\hline Total & 28,0284 & 8 & & & & \\
\hline
\end{tabular}

Figura 6. Quadro resumo da ANOVA fator único para o tamanho do grão.

SQ - Soma dos quadrados; gl - Graus de liberdade; MQ - Média dos Quadrados; F - Estatística F da Distribuição de Fischer-Snedecor (Valor calculado); valor-P - Valor de Probabilidade; F crítico - Estatística F da Distribuição de Fischer-Snedecor (Valor tabelado); TTAT - Tratamento Térmico para Alívio de Tensões; DC - Dupla Camada.

Tabela 4. Comparação das diferenças entre as variáveis pelo teste de Tukey

\begin{tabular}{lccccl}
\hline \multicolumn{1}{c}{ Comparação } & $\left|\mathbf{x}_{\mathbf{A}}-\mathbf{x}_{\mathbf{B}}\right|$ & d.m.s & Verificação & Conclusão \\
\hline Junta de referência com TTAT & 0,28 & 1,3968 & $0,28<1,3968$ & $\mu_{1}=\mu_{2}$ & Não diferem significativamente \\
Junta de referência com dupla camada & 3,74 & 1,3968 & $3,74>1,3968$ & $\mu_{1} \neq \mu_{3}$ & Diferem significativamente \\
Junta com TTAT e dupla camada & 3,46 & 1,3968 & $3,46>1,3968$ & $\mu_{2} \neq \mu_{4}$ & Diferem significativamente \\
\hline
\end{tabular}



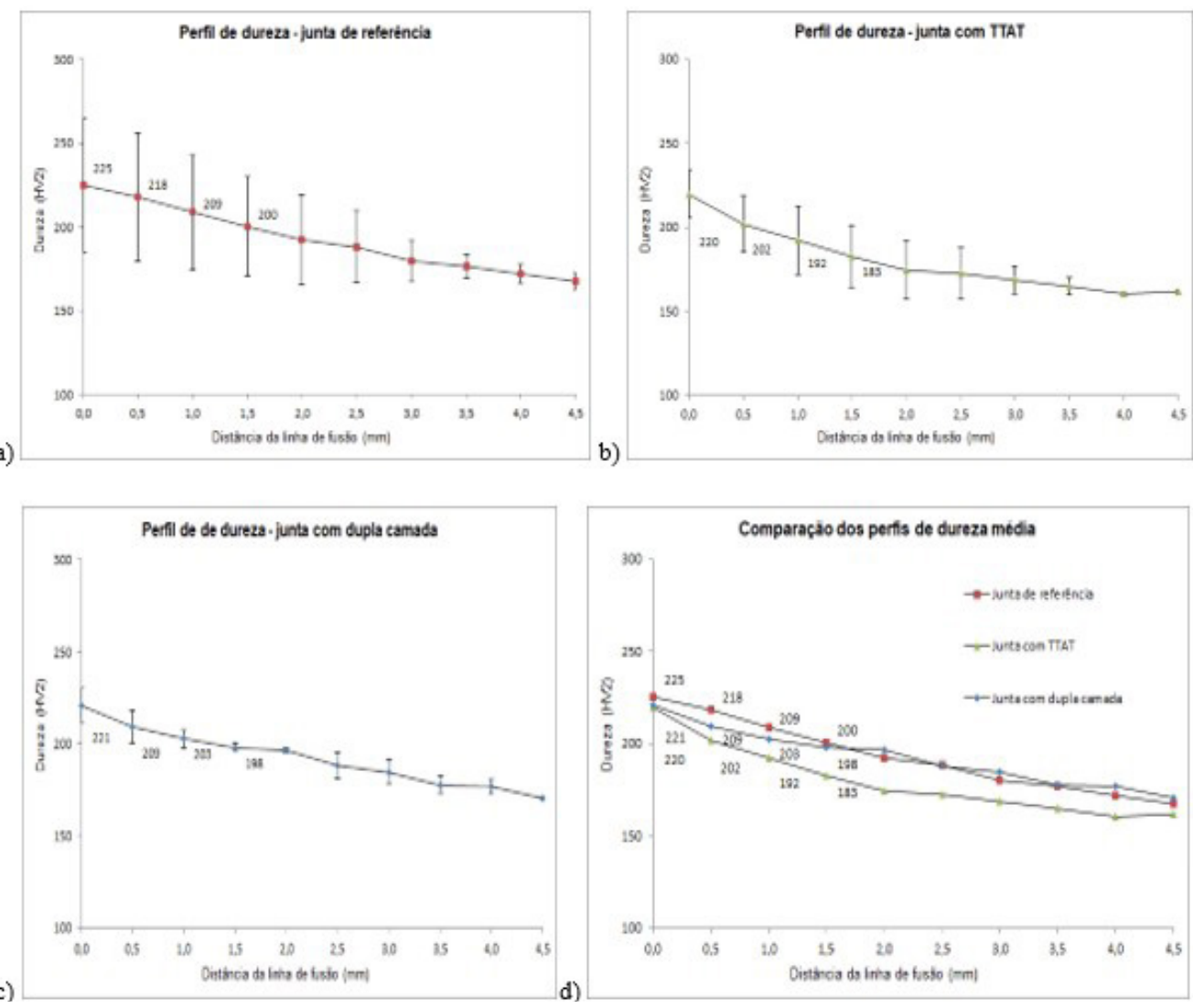

Figura 7. Perfis de dureza média: (a) amostra de referência; (b) com TTAT; (c) dupla camada; e (d) comparação dos perfis entre junta de referência, TTAT e com dupla camada.

\begin{tabular}{|c|c|c|c|c|c|c|}
\hline \multicolumn{5}{|l|}{ RESUMO } & & \\
\hline Grupo & Contagem & Soma & Média & Variância & & \\
\hline Junta de referência & 4 & 852 & 213,00 & 118,00 & & \\
\hline Junta com TTAT & 4 & 831 & 207,75 & 98,25 & & \\
\hline Junta com DC & 4 & 797 & 199,25 & 251,58 & & \\
\hline \multicolumn{7}{|l|}{ ANOVA } \\
\hline Fonte da variação & $S Q$ & $g l$ & $M Q$ & $F$ & valor $-P$ & F crítico \\
\hline Entre grupos & 385,166667 & 2 & 192,5833 & 1,234948 & 0,335794 & 4,256495 \\
\hline Dentro dos grupos & 1403,500000 & 9 & 155,9444 & & & \\
\hline Total & 1788,666667 & 11 & & & & \\
\hline
\end{tabular}

Figura 8. Quadro resumo da ANOVA fator único para a dureza.

diminuição de dureza na zona de crescimento de grão, a granulação da ZAC-GG da primeira camada não foi suficientemente refinada.

O segundo autor obteve o valor de dureza da ZAC-GG pela dupla camada reduzida para valores inferiores a $350 \mathrm{HV}$ e semelhantes às amostras de teste submetidas ao tratamento térmico. Nas regiões entre passes e as extremidades da junta, havia regiões com granulação grosseira, mas sem altos níveis de dureza.

\section{Conclusão}

Os resultados indicaram que houve variação significativa no tamanho de grão entre a amostra da junta de referência e com aplicação de tratamento térmico e da dupla camada, porém mantendo-se dentro da classificação como grãos fino-extrafinos. A dureza média diminuiu nas propostas avaliadas tanto para a amostra com tratamento de alívio de tensões quanto na aplicação da dupla camada 
não sendo consideradas significativamente diferentes. Os resultados são coerentes com os encontrados no estado da arte e contribuem para que técnica da dupla camada possa ser utilizada satisfatoriamente. Portanto a substituição do alívio de tensões térmico pela técnica da dupla camada pode ser realizada em casos onde componentes de grande porte torna o processo oneroso ou ainda dificultado por questões técnicas. Esta conclusão faz com que esta aplicação seja de grande valia na diminuição de custos e desenvolvimento de novos processos. Dentro disto, cabe salientar a importância da continuidade dos estudos de pesquisa e inovação da dupla camada em materiais que possuem características que possibilitem este tipo de metodologia.

\section{Agradecimentos}

Os autores deste trabalho agradecem a CAPES/FAPERGS (Anos de 2017-2018 - processo $\left.\mathrm{N}^{\circ} 8887.161019 / 2017-00\right)$ pelo suporte financeiro.

\section{Referências}

1 Niño CEB. Especificação de procedimentos de reparo por soldagem sem tratamento térmico posterior - efeito do revenimento produzido pelos ciclos térmicos [tese]. Florianópolis: Universidade Federal de Santa Catarina; 2001.

2 Meester B. The weldability of modern structural TMCP steels. ISIJ International. 1997;37(6):537-551.

3 Tsay LW, Chern TS, Gau CY, Yang JR. Microstructures and fatigue crack growth of EH 36 TMCP steel weldments. International Journal of Fatigue. 1999;21(8):857-864.

4 Cozza LM, Silva MF Jr, Medeiros JLB, Biehl LV, Martins COD, Souza J. Efeito do tratamento térmico de alivio de tensões na microestrutura e tamanho de grão de um aço microligado. Revista Liberato. 2018;19(31):58-67.

5 Ribeiro ACN, Henein H, Ivey DG, Brandi SD. Evaluation of AH36 microalloyed steel welded joint by submerged arc welding process with one and two wires. Materials Research. 2016;19(1):143-152.

6 Cozza LM, Medeiros JLB, Biehl LV, Souza J, Ferreira D Fo. Escolha das Energias de soldagem para aplicação na técnica da dupla camada na soldagem do aço ASTM 131 grau AH 36. Revista Soldagem \& Inspeção. 2019;24(1):e2405.

7 Cruz RLS. Avaliação dos efeitos da técnica da dupla camada na soldagem do aço ASTM A 516 grau 60 [dissertação]. Fortaleza: Universidade Federal do Ceará; 2006.

8 Azevedo AGL. Aplicação da técnica da dupla camada na soldagem do aço ABNT 1045 [dissertação]. Fortaleza: Universidade Federal do Ceará; 2002.

9 Farias JP, Aguiar WM. Soldagem do aço ABNT 4140 sem tratamento térmico posterior. Revista Tecnologia. 2003;24(1):26-36.

10 Aloraier A, Joshi S, Price JWH, Alawadhi K. Hardness, microstructure, and residual stresses in low carbon steel welding with post-weld heat treatment and temper bead welding. Metallurgical and Materials Transactions. A, Physical Metallurgy and Materials Science. 2014;45(4):2030-2037.

11 Cavalcante NE, Andrade TC, Pinheiro PHM, Miranda HC, Motta MF, Aguiar WM. Estudo de procedimentos de soldagem MIG/MAG para aplicação de revestimento de liga de níquel inconel 625 em aço estrutural ASTM A387 gr.11. Revista Soldagem \& Inspeção. 2016;21(1):70-82.

12 Silva CC, Albuquerque VHC, Moura CRO, Aguiar WM, Farias JP. Evaluation of AISI 4140 steel repair without post-weld heat treatment. Journal of Materials Engineering and Performance. 2009;18(3):324-331.

Recebido em: 20 Mar. 2020

Aceito em: 16 Jul. 2021 